\title{
Laboreal
}

Volume $3 \mathrm{~N}^{\circ} 2$ | 2007

Trabalho infantil

\section{Perspectivas acerca do trabalho infanto-juvenil : ideologias, subjectividade e saúde do trabalhador}

Perspectivas sobre el trabajo infanto-juvenil : ideologias, subjetividad y salud del trabajador

Perspectives à propos du travail infantile et juvénile : idéologies, subjectivité et santé du travailleur.

Perspectives on child labour : ideologies, subjectivity and workers' health

Mayte Amazarray, Luciana Thomé, Michele Poletto e Sílvia Koller

\section{(2) OpenEdition}

Journals

Edição electrónica

URL: http://journals.openedition.org/laboreal/12321

DOI: 10.4000/laboreal.12321

ISSN: 1646-5237

\section{Editora}

Universidade do Porto

\section{Refêrencia eletrónica}

Mayte Amazarray, Luciana Thomé, Michele Poletto e Sílvia Koller, «Perspectivas acerca do trabalho infanto-juvenil : ideologias, subjectividade e saúde do trabalhador », Laboreal [Online], Volume 3 NN$^{0} 2$ I 2007, posto online no dia 01 dezembro 2007, consultado o 10 outubro 2019. URL : http:// journals.openedition.org/laboreal/12321 ; DOI : 10.4000/laboreal.12321

Este documento foi criado de forma automática no dia 10 outubro 2019. 


\section{Perspectivas acerca do trabalho infanto-juvenil : ideologias, subjectividade e saúde do trabalhador}

Perspectivas sobre el trabajo infanto-juvenil : ideologias, subjetividad y salud del trabajador

Perspectives à propos du travail infantile et juvénile : idéologies, subjectivité et santé du travailleur.

Perspectives on child labour : ideologies, subjectivity and workers' health

Mayte Amazarray, Luciana Thomé, Michele Poletto e Sílvia Koller

\section{NOTA DO EDITOR}

Manuscrito recebido em : Março/2007

Aceite após peritagem em : Setembro/2007

\section{Introdução}

1 O trabalho infanto-juvenil tornou-se temática de destaque internacional, especialmente devido aos impactos desta atividade no desenvolvimento infantil e na saúde de crianças e adolescentes. Também chama a atenção o fato de que o envolvimento precoce em atividades econômicas está associado a contextos de pobreza, violência e condições precárias de moradia e trabalho. Tendo em vista nosso trabalho de investigação junto a populações em situação de risco social, o Centro de Estudos Psicológicos sobre Meninos e Meninas de Rua (CEP-RUA), vinculado ao Instituto de Psicologia da Universidade Federal do Rio Grande do Sul (Porto Alegre, Brasil), constituiu um Núcleo de Estudos e 
Pesquisas sobre Trabalho. 0 núcleo, cujo objetivo é a promoção de estudos que tomem a categoria trabalho como central no processo de desenvolvimento humano, tem buscado investigar e discutir os aspectos psicológicos, sociais e econômicos que permeiam o trabalho infanto-juvenil, com ênfase em políticas públicas, contextos familiares e sociais, direitos da criança e do adolescente, impactos na saúde e bem-estar.

2 No presente artigo, apresentaremos algumas reflexões a respeito do trabalho infantojuvenil, apontando diferentes perspectivas acerca do tema. Embora não tenhamos a pretensão de esgotar os diversos pontos de vista e enfoques que tal temática pode suscitar, iremos discorrer sobre três tópicos centrais: ideologias que sustentam o trabalho precoce ; subjetividade da criança e do adolescente em situação de trabalho e saúde do trabalhador infantil. A perspectiva teórica que sustenta nosso olhar e articula esses três enfoques é a Abordagem Bioecológica do Desenvolvimento Humano, uma teoria contextualista e interacionista, segundo a qual os processos se dão dentro de contextos através de interações em diversos níveis de diferentes sistemas (Bronfenbrenner, 2005; Narvaz \& Koller, 2004). Portanto, nosso olhar sobre o desenvolvimento das crianças e adolescentes trabalhadores considera, necessariamente, seus contextos familiares e sociais, bem como os processos proximais que estabelecem ao longo do tempo.

3 O termo trabalho infantil pode referir-se a muitas atividades, remuneradas ou não, com diferentes graus de risco e em diversos setores e contextos. A compreensão de trabalho infantil que norteia esse estudo está embasada na definição proposta pela Organização Internacional do Trabalho OIT (2004), podendo ser caracterizado como aquele que priva as crianças de sua infância, potencial e dignidade, sendo nocivo para o seu desenvolvimento. Neste sentido, diz respeito ao trabalho que é física, mental, social ou moralmente prejudicial para a criança e que interfere em sua escolarização, especialmente quando a impede de freqüentar a escola, abandonando prematuramente as aulas ou mesmo exigindo que a criança concilie atividades escolares com longas jornadas de trabalho pesado.

4 Por outro lado, a OIT (2004) reconhece que algumas formas de trabalho podem ser consideradas positivas, desde que não interfiram na escolarização e não afetem a saúde e o desenvolvimento de crianças e adolescentes. É o caso de pequenas ajudas aos pais nas tarefas domésticas ou em negócios familiares, assim como o envolvimento em atividades remuneradas visando a gastos pessoais e realizadas fora do horário da escola. Esse tipo de trabalho não é alvo dos programas de erradicação, na medida em que pode contribuir para o bem-estar das crianças e de suas famílias, facilitando a aquisição de habilidades e auxiliando no processo de desenvolvimento e futura inserção no mercado de trabalho. Diante disso, reiteramos a concepção de trabalho infantil preconizada pela OIT e salientamos a importância de considerar o contexto das crianças e adolescentes que exercem alguma atividade de trabalho. A análise do risco envolvido no trabalho infantil deve avaliar, caso a caso, os fatores positivos que essa atividade pode potencialmente oferecer. Nesse sentido, partilhamos também da concepção de Fukui, Sampaio e Brioschi (1985), segundo a qual nem todas as formas de trabalho infantil devem ser abolidas. Há situações em que a execução de certas atividades pode estar adequada à maturidade física e emocional da criança, possibilitando o desenvolvimento de um senso de responsabilidade e socialização.

5 No Brasil, o trabalho infantil vem sendo um assunto amplamente debatido na mídia e no âmbito social. As atividades que mais exploram a mão-de-obra infantil são as 
agrícolas e, na área urbana, atividades realizadas em ruas, feiras e lixões. Segundo o último relatório da OIT (2006), o Brasil é o país das Américas e do Caribe que mais reduziu o trabalho infantil, principalmente em suas piores formas, nos últimos anos. A faixa etária dos 10 aos 17 anos teve uma redução de 36,4 \% de 1992 a 2004 : de cerca de 7,5 milhões para aproximadamente 4,8 milhões. No grupo das crianças de cinco a nove anos, a diminuição foi ainda maior, $60,9 \%$, sendo que de 636.248 reduziu-se para 248.594. Em 2006, 12.458 crianças e adolescentes envolvidas no trabalho precoce foram retiradas dessas ocupações (ILO, 2006 ; OIT, 2006).

6 A introdução do Estatuto da Criança e do Adolescente ECA, em 1990 (Brasil, 1990), constitui um marco na legislação brasileira no que diz respeito à garantia dos direitos das crianças e dos adolescentes. Segundo o ECA, artigo 60, é proibido qualquer trabalho a menores de quatorze anos, salvo na condição de aprendiz. A legislação também estabelece diretrizes quanto à proteção do trabalho do adolescente e enfatiza a educação. O ECA tem sido um instrumento legal de extrema relevância subsidiar a implementação de programas e políticas públicas voltadas à erradicação das piores formas de trabalho infantil no Brasil.

7 Apesar da redução das piores formas de trabalho infantil conquistada nos últimos anos, ainda persiste um grande número de crianças e adolescentes que participam de atividades econômicas, inclusive daquelas que envolvem tráfico de drogas e exploração sexual. Além dos fatores econômicos, a complexidade do tema é perpassada por questões culturais e ideológicas, as quais estão intimamente associadas à dificuldade da erradicação do trabalho infantil e à mudança de comportamento necessária para tal finalidade. A seguir, abordaremos este aspecto, destacando a construção histórica da prática do trabalho infantil, a partir da Idade Moderna, bem como questões ideológicas que contribuem para a sua manutenção nos dias atuais.

\section{Ideologias e trabalho precoce}

8 Ao longo da história da civilização humana, a crise social e econômica, a pobreza e o desemprego crescentes que atingem uma parcela importante da população aparecem combinados a uma transformação social de amplas proporções, na qual despontam o desenvolvimento tecnológico, a desaparição de fronteiras e uma concentração de renda. Este é o cenário em que se movem crianças e adolescentes trabalhadores, embora o trabalho precoce não seja um problema apenas de países pobres e subdesenvolvidos. De acordo com estimativa da OIT (2006), existem no mundo mais de 246 milhões de crianças e adolescentes trabalhadores com idade entre cinco e 17 anos. Desses, mais de 100 milhões não têm acesso a qualquer tipo de educação e, para a maioria, tempo para brincar é um luxo que não está ao seu alcance. De fato, há consideráveis diferenças de escala e de foco do trabalho infantil entre países subdesenvolvidos, como é o caso do Brasil e de outros países em desenvolvimento. Em nações desenvolvidas, o trabalho infantil aparece em menor escala e pouco associado à evasão escolar, enquanto nas subdesenvolvidas essa temática compromete o desenvolvimento sustentável e tende a ser uma prática mais generalizada.

9 Apesar dessas diferenças, desde os séculos XVII a XIX, a participação de crianças no mercado de trabalho é de conhecimento público e mundial. Marx (1867/1996), em sua obra O Capital, comenta a exploração da mão-de-obra infantil e analisa vários processos relacionados ao trabalho de crianças e adolescentes nas fábricas. Um deles se refere ao 
fato de que o emprego de crianças era uma forma de elevar as taxas de lucro, já que a mão-de-obra infantil era de baixo custo. Além disso, as crianças eram vistas como mais dóceis e capazes de sofrer dominação do que os adultos e, certamente, muitas delas também fizeram parte do exército industrial de reserva em épocas de guerras e crises econômicas pelo mundo. Assim como na Inglaterra, a história da industrialização no Brasil também foi marcada pela utilização de mão-de-obra infantil (ILO, 2006).

o modo de produção dominante em determinado momento histórico, que convive com outros modos de produção subordinados, determina a organização e a execução dos processos de trabalho e suas respectivas organizações técnicas, produto das relações sociais. A exploração da mão-de-obra infantil está vinculada a esse circuito que, por vezes, incorpora crianças ao mercado de trabalho, enquanto, por outro lado, há mãode-obra adulta excedente (Oliveira, 1987; Assunção \& Dias, 2002). O fenômeno do trabalho infanto-juvenil pode ser compreendido através do mecanismo intrínseco ao capitalismo, o qual gera pobreza e cria as condições para a reprodução do fenômeno da inserção precoce de crianças no trabalho (Campos, 2001).

o contexto sócio-histórico em que o indivíduo está inserido o envolve de tal forma que suas atitudes e pensamentos não podem ser dissociados deste entorno. As ideologias que permeiam o trabalho modificam-se no decorrer da história e atravessam este mesmo ser humano. Campos e Alverga (2001) apontam a importante mudança na concepção de trabalho, de uma perspectiva que remete ao ócio e à contemplação para uma perspectiva fundamentada na ética do trabalho e na boa formação do sujeito. Esta última lógica passou a dominar a cultura ocidental, como foi apontado por Weber (2004). Entretanto, essa perspectiva ética do trabalho prestava-se, também, à discriminação entre as classes, já que aos nobres destinava-se o trabalho intelectual e aos pobres o trabalho manual, fabril, artesanal, agrícola etc., com status de indignidade.

Neste sentido, a compreensão da ética do trabalho direcionou milhares de crianças para a indústria capitalista inglesa, sob proteção de uma lógica que exaltava a formação moral do sujeito. Famílias miseráveis alugavam seus filhos para fábricas, centradas na busca de lucro. Essa perspectiva tomou proporções legais pela primeira vez em 1854, através do Regulamento da Instrução Primária e Secundária do Município Neutro que defendia a criação de entidades profissionalizantes para "os meninos pobres e indigentes a partir dos 12 anos que vagavam pelas ruas" (Campos \& Alverga, 2001). Segue o discurso ideológico de discriminação, que entende como crianças os filhos da nobreza, e, como "menores", os meninos que viviam nas ruas.

13 A exploração do trabalho infantil persiste na contemporaneidade devido a uma combinação de fatores, como a condição de miserabilidade e vulnerabilidade das famílias, a ausência de políticas públicas e a péssima distribuição de renda no Brasil (Marques, Neves \& Neto, 2002). Neste cenário, a criança se vê obrigada a trabalhar para garantir seu sustento próprio ou de sua família. Não é incomum que o trabalho infantil seja concebido como parte complementar das atribuições familiares, segundo a lógica das obrigações, que caracteriza as relações nas famílias carentes (Sarti, 1996). Segundo Barros e Santos (1996), o trabalho infantil é um dos mecanismos de transmissão intergeracional da pobreza, especialmente porque, em geral, os pais das crianças trabalhadoras também realizaram esta atividade na sua infância.

14 No entanto, além de questões econômicas, também é certo que determinados fatores culturais encontram-se imbricados nas formas de organização da família. Tais fatores expressamse nas relações entre adultos e crianças, na concepção sobre os gêneros e 
idades e nas formas de reciprocidade presentes no grupo familiar. Cabe refletir sobre os discursos e práticas produzidos no Brasil sobre o trabalho no século XIX, atentando para o fato de estarem muitas vezes arraigados nas instituições responsáveis pela socialização das crianças trabalhadoras, como a família e a escola. Um estudo desenvolvido por Feitosa e Dimenstein (2005) exemplifica esse aspecto. A pesquisa foi realizada com grupos focais, cujos participantes eram mães de crianças que estudam e trabalham no cultivo de hortas em Gramorezinho (Natal, Brasil). Para essas mães, o trabalho infantil é visto como parte integrante da atividade de agricultura familiar. Muitas vezes, elas próprias introduzem as crianças no mundo do trabalho, levando seus filhos desde bebês para as hortas, de forma que já possam aprender com a produção além de não terem onde deixar as crianças. As atividades laborais iniciam-se em meio a brincadeiras, tomando, com o passar do tempo, caráter de obrigatoriedade. Por outro lado, preocupavam-se com o tempo vago de seus filhos, percebendo a falta de condições de oferecer outras possibilidades às crianças, como deixar o filho desfrutar de brincadeiras ou de cursos de computação e idiomas. A única alternativa para preencher o tempo ocioso dos filhos era com trabalho. Além disso, o discurso das mães revelava que a inserção da ideologia do trabalho está imersa nas suas práticas educativas. Assim, as mães atuam como reprodutoras de uma vivência de trabalho para os filhos.

Dessa forma, o trabalho infantil apresenta-se como uma prática reforçada também pela família, o que também é apontado por outros autores (Campos \& Alverga, 2001). Os aspectos subjetivos dos sujeitos envolvidos, portanto, devem ser levados em consideração, pois muitas vezes as crenças, padrões e significados dados por essas famílias ao trabalho infantil intensificam essa prática. Feitosa e Dimenstein (2005) corroboram esta idéia ao observarem que, mesmo com políticas diversas de erradicação do trabalho infantil, a família é um dos propulsores da inserção precoce no trabalho. Percebe-se, aí, como a ideologia do trabalho está presente nos discursos e práticas dos sujeitos. Ainda que para algumas mães a experiência de trabalho tenha sido triste e sofrida, esta vivência está tão presente em suas vidas que muitas vezes representa o saber que podem transmitir transgeracionalmente para seus filhos. Tal fato demonstra o quanto a experiência laboral é definidora de suas identidades, bem como das identidades de seus filhos, precocemente inseridos no mundo do trabalho. Neste sentido, evidencia-se a perspectiva da subjetividade, a qual pode ampliar a compreensão do fenômeno do trabalho infanto-juvenil, exposta a seguir.

\section{Subjetividade da criança e do adolescente em situação de trabalho}

16 A Psicologia pode ampliar seu espaço de investigação acerca da temática do trabalho infanto-juvenil introduzindo a perspectiva da subjetividade, a qual busca compreender o impacto dessa situação na constituição e desenvolvimento das crianças e adolescentes. Compreende-se, aqui, subjetividade como "expressão dos contextos sociais e relacionais em que o sujeito está inserido e o sentido subjetivo que estes assumem" (Martinez, 2001, p. 238), não sendo apenas um produto da interação do social e do biológico, mas de todo um conjunto de complexas relações das quais a pessoa participa em seus múltiplos contextos. Perspectiva esta que também resulta do nosso olhar a partir da abordagem bioecológica do desenvolvimento humano (Narvaz \& Koller, 2004). Nesse sentido, a relação de trabalho contribui para a constituição do 
mundo psicológico do indivíduo, compreendendo-a como atividade geradora das condições que possibilitam explicar o salto qualitativo do psiquismo animal para o psiquismo humano (Albornoz, 1994 ; Codo, 1997).

Na perspectiva do impacto na formação da subjetividade, o trabalho infantil limita a participação dos pequenos trabalhadores nos espaços relacionais mais favoráveis para o desenvolvimento de recursos subjetivos desejáveis, como a família, a escola e o tempo para brincar. Por outro lado, ao olhar para as formas com que crianças e adolescentes significam suas experiências de trabalho torna-se possível questionar o caráter absoluto que assumem certas afirmações sobre as conseqüências psicológicas do trabalho infantil, tais como o comprometimento do desenvolvimento físico, cognitivo e emocional, cancelamento de projetos de vida e desestruturação do mundo infantil. Compreende-se que estas afirmações se apliquem à experiência de muitas crianças e adolescentes trabalhadores, todavia, não necessariamente se aplicam às vivências de outros. Por exemplo, Martinez (2001) aponta um estudo exploratório realizado com adolescentes trabalhadores em Brasília (Distrito Federal, Brasil), no qual estes percebem sua experiência laboral como libertadora, permitindo-lhes seguir seus projetos de vida, enquanto que a escola é vivenciada como espaço de dever.

Forastieri (1997) destaca a contribuição do trabalho para o crescimento como pessoa ou cidadão, incorporando sentimentos de auto-estima e realização à sua personalidade, desde que compatível e equilibrado com seu potencial. Um estudo realizado por Oliveira, Fischer, Amaral, Teixeira e Sá (2005) identificou outros aspectos positivos associados ao trabalho: identificam as funções de crescimento, desenvolvimento humano, estimulação da criatividade e aprovação social advindas dessa atividade. Além destes, dinheiro e senso de responsabilidade também aparecem como conseqüências positivas diretas ou indiretas. Outro estudo, desenvolvido em Minas Gerais por Marques, Neves e Neto (2002), identificou o prazer no ato de brincar no trabalho em diversas falas de crianças trabalhadoras: muitas transformam os carrinhos de feiras (instrumentos de trabalho) em objetos lúdicos. Ainda que a criança trabalhadora possa apresentar-se séria e tranqüila, adotando uma postura adulta precoce, mostra-se criança especialmente ao abrir espaços para a brincadeira no seu trabalho (Bonamigo, 1996).

19 Enquanto atividade remunerada e aprendizado de um ofício, o trabalho reveste-se de um sentido de aquisição de uma identidade social legítima para os jovens e suas famílias (Heilborn, 2000). O trabalho fornece, de acordo com Gouveia (1983), status na família. A criança ou o adolescente trabalhador sente-se mais seguro para reagir quando submetido a tratamento disciplinar mais severo na família e, ao mesmo tempo, demonstra sentimento de auto-realização, evidenciando orgulho por trabalhar. 0 trabalho funciona como um mecanismo disciplinador e como forma de inserção aceita socialmente no mundo.

20 A inserção da criança no mercado de trabalho provoca modificações na relação com a família. Diversos autores (Gouveia, 1983; Vogel \& Mello, 1996) mencionam e discutem tais transformações na dinâmica do grupo familiar. Através do trabalho, a criança adquire o valor das conquistas pelo próprio esforço, certa independência relativa da família, status diferenciado e possibilidade de ter bens que seus pais não poderiam oferecer. Ela costuma ser vista como mais responsável, calma, educada, satisfeita, independente, menos exigente e brigona (Vogel \& Mello, 1996). A família, então, se dá 
conta de que a criança, ao trabalhar, leva vida de adulto e, ela por sua vez, constata que é mais ouvida e menos punida pela família.

21 Um estudo desenvolvido por Bonamigo (1996) mostrou que meninos trabalhadores percebem seu trabalho como algo que gera sofrimento e, ao mesmo tempo, satisfação. Estabelece-se uma relação ambígua: de um lado, há valorização do trabalho pela aquisição de características positivas e pela distância em relação às atividades marginais. Do outro, o sofrimento pela dura realidade que vivem. É a ambigüidade de afetos e sentimentos (prazer versus sofrimento) em relação ao trabalho que denota a importância de considerá-lo, em seus aspectos positivos e negativos, tendo em vista o seu papel na constituição do psiquismo de crianças e adolescentes trabalhadores. Trabalhos de investigação e programas de intervenção junto a essa população devem escutar a fala dos pequenos trabalhadores, a fim de compreender o significado do trabalho em suas vidas, assim como visando à construção de outros sentidos, que favoreçam a promoção de sua saúde.

\section{Saúde do trabalhador infantil}

22 Há um reconhecimento acerca da importância do trabalho na vida do ser humano e no seu desenvolvimento ao longo do ciclo vital. Contudo, a atividade de trabalho requer maturidade física, mental e moral para sua execução, de modo a que o trabalho seja promotor de significado e prazer para o trabalhador. A partir desses pressupostos, cabe a preocupação acerca dos impactos do trabalho precoce na saúde de crianças e adolescentes trabalhadores, em especial quando se trata das piores formas de trabalho infantil (trabalho forçado, tráfico de drogas, conflitos armados, exploração sexual, atividades insalubres e perigosas, entre outras).

As crianças tendem a ser mais vulneráveis às doenças e aos acidentes de trabalho, tanto para desenvolvê-las de forma precoce quanto com maior gravidade. Isto se deve a uma série de fatores, entre os quais podemos citar : imaturidade e inexperiência, distração e curiosidade próprias à idade, pouca resistência física, menor coordenação motora (quanto menor a idade), desconhecimento dos riscos do trabalho, tarefas inadequadas a sua capacidade, locais e instrumentos de trabalho desenhados para adultos (Assunção \& Dias, 2002; Franklin et al., 2001). Além disso, não é incomum que crianças e adolescentes sejam levados a exercer funções que são consideradas inseguras até mesmo para os adultos. Não se pode perder de vista que essa população se encontra em fase de crescimento e desenvolvimento, apresentando capacidades, limitações e reações orgânicas distintas dos adultos (Asmus, Raymundo, Barker, Pepe \& Ruzany, 2005). Nesse sentido, as condições de trabalho, em geral, são contraditórias com o desenvolvimento do trabalhador infantil (Assunção \& Dias, 2002).

Asmus et al. (2005) chamam a atenção para o fato de que existem períodos críticos no estágio de desenvolvimento de determinadas estruturas funcionais, que estariam mais propensas a sofrer lesões em razão dos riscos do trabalho. Além disso, destacam que alguns danos podem não ser evidentes de imediato, manifestando-se somente em estágios posteriores da vida. A exaustão e a fadiga decorrentes das cargas de trabalho excessivas, associadas a uma nutrição deficiente, são apontadas por Asmus et al. (2005) como as principais causas para o surgimento de patologias entre os adolescentes que freqüentam o Programa de Saúde do Trabalhador Adolescente, vinculado à Universidade Estadual do Rio de Janeiro, Brasil. 
25 A OIT (2004) aponta diversos riscos e conseqüências relacionadas às diferentes atividades desempenhadas pelos trabalhadores infanto-juvenis. Os riscos envolvem maquinário e ferramentas sem proteção, ruído, vibrações, exposição a produtos químicos e agentes biológicos, exposição a temperaturas extremas, cargas pesadas, posturas inadequadas, movimentos repetitivos, entre outros, nos setores agrícola e industrial. Quanto ao trabalho nas ruas, os riscos envolvem exposição a drogas, violência, prostituição, acidentes de trânsito, participação em delitos, entre outros. Um estudo do Instituto Brasileiro de Geografia e Estatística IBGE (2003) aponta que aproximadamente metade das crianças e adolescentes brasileiros ocupados utiliza produto químico, máquina, ferramenta ou instrumento de trabalho. Uma parcela ainda maior foi verificada entre os que trabalhavam em atividades agrícolas.

26 A lista de fatores de risco é extensa e nos permite ter uma noção da periculosidade, insalubridade e penosidade envolvidas no trabalho infantil, constituindo-se não apenas em fatores causadores de doenças e acidentes, mas também em atentados contra a dignidade de crianças e adolescentes. No que diz respeito às conseqüências para a saúde, a OIT (2004) aponta uma diversidade de danos, entre os quais podemos citar: fraturas, cortes, amputações, perda auditiva, lesões cerebrais e oculares, infecções, intoxicações, queimaduras, transtornos músculo-esqueléticos, doenças respiratórias, drogadição, fadiga, desnutrição, AIDS e outras doenças sexualmente transmissíveis, gravidez indesejada, estigma social ligado à delinqüência, entre outras. A morte também é relatada como uma possível conseqüência do trabalho precoce. Assunção \& Dias (2002) salientam, ainda, a privação do sono, que comumente se dá entre crianças e adolescentes trabalhadores. Envolvidos em longas jornadas de trabalho e, por vezes, necessitando conciliá-las com outras tarefas, como escola e responsabilidades domésticas, crianças e adolescentes têm seu desenvolvimento seriamente prejudicado devido aos efeitos cumulativos da falta de sono e da fadiga.

Cabe, ainda, destacar os aspectos sociais e de saúde mental envolvidos no trabalho precoce. O relacionamento da criança e do adolescente com o seu meio apresenta peculiaridades que o diferem claramente do adulto. Se, por um lado, procuram preservar sua capacidade de brincar em meio às exigências laborais, por outro lado, sua sensibilidade e vulnerabilidade às agressões ambientais são notadamente mais elevadas. Além disso, as tarefas e responsabilidades impostas às crianças e adolescentes no trabalho precoce dificultam seu processo de aprendizagem, impedindo o contato e a exploração de outros ambientes, o desenvolvimento de potencialidades, o relacionamento com outras crianças e pessoas significativas. Assunção \& Dias (2002) apontam a tolerância à desumanização presente em boa parte dos processos produtivos: regras coercitivas e disciplina rígida, deixando pouco espaço para os mecanismos de auto-regulação do ser humano; negligência com os mecanismos coletivos de proteção contra os fatores de risco, ausência de conforto, estímulo à competição, etc. Os efeitos desses fatores na saúde mental de crianças e adolescentes podem ser diversos, dentre os quais se pode pensar em limitações cognitivas, bloqueio da imaginação e criatividade e empobrecimento de relações sociais e afetivas.

\section{Trabalho infantil e produção cientifica em Psicologia}

A produção científica acerca do trabalho infantil no âmbito da Psicologia brasileira ainda é escassa, em contraponto à importância do tema. Realizou-se um levantamento 
das publicações nos periódicos nacionais na Biblioteca Virtual em Saúde Psicologia (http://www.bvs-psi.org.br). O levantamento do número de trabalhos publicados gerou 16 resultados. Após a análise dos materiais, categorizaram-se os temas problematizados e os métodos de pesquisa utilizados pelos autores. 0 ano de 2001 destacou-se devido ao maior número de publicações por ano : sete, o qual coincide com a publicação de um dossiê especial sobre o tema em um dos periódicos nacionais. Esse número de publicações pode ser considerado muito baixo se comparado ao total de artigos publicados na área da Psicologia como um todo no Brasil a cada ano.

Os temas problematizados nos artigos encontrados envolvem, principalmente, os efeitos do trabalho sobre o desenvolvimento de crianças e adolescentes, ações políticas e sociais de erradicação do trabalho infantil e características e concepções deste fenômeno. Os métodos utilizados envolvem basicamente levantamento bibliográfico e apenas seis artigos são estudos exploratórios descritivos apresentando crianças e adolescentes trabalhadores como participantes diretos. Esses dados revelam que, apesar da grande mobilização mundial contra o trabalho infantil, esta temática ainda não recebeu a devida atenção da área da Psicologia no Brasil. o pequeno número de publicações aponta que este fenômeno necessita de mais investimento científico e social.

\section{Considerações finais}

30 A fim de contribuir para a compreensão do tema, o presente artigo buscou agregar ao tema trabalho infantil a perspectiva das concepções ideológicas que permeiam esta prática, a subjetividade e a saúde do trabalhador infantil. Entendemos que a questão deve ser olhada globalmente, devido à complexidade dos aspectos envolvidos: ideológicos, culturais, econômicos etc. Os programas governamentais que se propõem a erradicar tal problema social podem tomar essas três perspectivas como base na organização de suas ações, de forma que as mesmas tornem-se mais efetivas e eficazes.

Uma constatação importante deste estudo é que a perspectiva das crianças e adolescentes trabalhadores quase nunca é considerada, priorizando-se o ponto de vista do adulto. Ao promover ações de erradicação devemos nos perguntar : que ser humano está se formando a partir daquela experiência de trabalho? Que valores estão sendo construídos? Os estudos podem ouvir o que a criança tem a dizer sobre o trabalho, pois é um ser com voz ativa. Dar voz à criança e ao adolescente pode ser, também, a base de programas educativos com crianças e suas famílias.

32 Voltamos, também, o olhar para os aspectos ideológicos, numa tentativa de compreender as forças sócio-históricas e culturais que envolvem a temática do trabalho infantil. Essa perspectiva pode nos auxiliar no entendimento das lógicas que mantém a exposição destas crianças e adolescentes ao trabalho precoce, seja através da própria família ou de outras instituições que atravessam seus agentes.

Finalmente, os agravos à saúde relacionados ao trabalho precoce nos fazem ter uma noção dos impactos negativos do trabalho infanto-juvenil. No tocante à saúde física, trata-se de conseqüências visíveis, que denunciam a gravidade da situação. Por outro lado, as questões relativas à saúde mental, justamente por não serem explícitas e imediatas, necessitam de maior investigação. Seria recomendável, por exemplo, desenvolver estudos longitudinais que acompanhem o desenvolvimento de crianças e 
adolescentes trabalhadores, em diferentes setores ocupacionais. Além dos riscos e conseqüências negativas, uma compreensão global do fenômeno deve, ainda, buscar conhecer os aspectos positivos do trabalho, na visão das próprias crianças e adolescentes, assim como nas potencialidades que esses trabalhadores possam desenvolver.

\section{BIBLIOGRAFIA}

Albornoz, S. (1994). O que é trabalho ? 6.ed. São Paulo : Brasiliense. Asmus, C. I. R. F., Raymundo, C. M., Barker, S. L., Pepe, C. C. C. A., \&

Ruzany, M. H. (2005). Atenção integral à saúde de adolescentes em situação de trabalho : lições aprendidas. Ciência e Saúde Coletiva, 10,(4), 953-960.

Assunção, A. A., \& Dias, E. C. (2002). Trabalho precoce : possíveis efeitos sobre o desenvolvimento das crianças e adolescentes. Revista Devir : esquizoanálise e seus encontros, 1, (2), 39-60.

Barros, R. P. de \& Santos, E. C. (1996). Conseqüências de longo prazo do trabalho precoce. In A. Fausto \& R. Cervini (Eds.), O trabalho e a rua : Crianças e adolescentes no Brasil urbano dos anos 80 (pp. 56-61). 2. ed. São Paulo : Cortez.

Bonamigo, L. de R. (1996). O trabalho e a construção da identidade : Um estudo sobre meninos trabalhadores na rua. Psicologia : Reflexão e Crítica, 9, (1), 129-152.

Brasil (1990). Estatuto da Criança e do Adolescente - Lei Federal 8069/1990. Brasília.

Bronfenbrenner, U. (2005). The bioecological theory of human development. In U. Bronfenbrenner (Ed.), Making human beings human : Bioecological perspectives on human development (pp. 3-15). Thousand Oaks, CA : Sage (First published in 2001).

Campos, H. R. (2001). Pobreza e trabalho infantil sob o capitalismo. Tese de Doutorado Inédita. Pós-Graduação em Educação. Universidade Federal do Rio Grande do Norte. Natal, Rio Grande do Norte, Brasil.

Campos, H. R., \& Alverga. R. de. (2001). Trabalho infantil e ideologia : contribuição ao estudo da crença indiscriminada na dignidade do trabalho. Estudos de psicologia, 6, (2), 227-233.

Codo, W. (1997). Um diagnóstico do trabalho (em busca do prazer). In A. Tamayo, J. E. BorgesAndrade, \& W. Codo (Eds.), Trabalho, organizações e cultura (pp. 21-40). São Paulo : Cooperativa de Autores Associados.

Feitosa, I. \& Dimenstein, M. (2005). Trabalho infantil e ideologia nas falas de mães de crianças trabalhadoras. Retrieved in August 10, 2005, from http://www2.uerj.br/ revispsi/v4n2/artigos/ ARTIGO4.html

Forastieri, V. (1997) Children at work : health and safety risks. International Labour Office, Geneva.

Franklin, R.N., Pinto, E.C.M.M., Lucas, J.T., Linné, M., Peixoto, R., Sauer, M.T.N., Silva, C.H., Nader, P.J.H. (2001). Trabalho precoce e riscos à saúde. Adolescência Latinoamericana, 2, (2), 80-89. 
Fukui, L. F. G., Sampaio, E. M. S. \& Brioschi, L. R. (1985). A questão do trabalho infantil na grande imprensa paulista na década de 70. Revista Brasileira de Estudos Pedagógicos, 66, (152), 28-46.

Gouveia, A. J. (1983). O trabalho do menor : Necessidade transfigurada em virtude. Cadernos de Pesquisa, 44, 55-62.

Heilborn, M. L. (2000). Dimensões Culturais do Trabalho Infantil Feminino. Revista Eletrônica. Retrieved in August, 17, 2005, from http:// www.ilo.org/public/english/standards/ipec/publ/ policy/papers/brasil/ oitheilborn.pdf.

International Labour Office (2006). The end of child labour : within reach. Global report under the follow-up to the ILO Declaration on Fundamental Principles and Rights at Work. Retrieved in August 22, 2006, from www.ilo.org/declaration.

Instituto Brasileiro de Geografia e Estatística (2003). Pesquisa nacional por amostra de domicílios : trabalho infantil 2001. Retrieved in March, 12, 2007, from www.ibge.gov.br/home/ estatistica/populacao/condicaodevida/trabalho_infantil/default.shtm

Martinez, A. M. (2001). Trabajo Infantil y Subjetividad : una perspectiva necesaria. Estudos de psicologia, 6, (2), 235-244.

Marques, M. E., Neves, M. de A. \& Neto, A. C. (2002). Trabalho infantil : a infância roubada. Belo Horizonte : Segrac.

Marx, K. (1996). O capital : crítica da economia política. (Vol.1) Rio de Janeiro : Bertrand Brasil. (Original publicado em 1867).

Narvaz, M. G., \& Koller, S. H. (2004). O modelo bioecológico do desenvolvimento humano. In S. H. Koller (Ed.), Ecologia do desenvolvimento humano : pesquisa e intervenção no Brasil (pp. 51-65). São Paulo : Casa do Psicólogo.

Oliveira, C. R. de. (1987). História do trabalho. São Paulo : Ática. Oliveira, D. C., Fischer, F. M. ; Amaral, M. A. ; Teixeira, M. C. T. V., \& Sá, C. P. (2005) A positividade e a negatividade do trabalho nas representações sociais de adolescentes. Psicologia Reflexão e Crítica, 18, (1), 125-133.

Organización Internacional del Trabajo (2004). Trabajo infantil : un manual para estudiantes. Oficina Internacional del Trabajo : Ginebra.

Organização Internacional do Trabalho (2006). A eliminação do trabalho infantil : um objetivo ao nosso alcance. Relatório Global 2006 - Suplemento Brasil. Retrieved in March, 12, 2007, from http://www.oitbrasil.org.br

Sarti, C. A. (1996). A família como espelho. São Paulo : Autores Associados.

Vogel, A. \& Mello, M. A. A. da S. (1996). Da casa à rua : a cidade como fascínio e descaminho. In A. Fausto \& R. Cervini (Eds.), O trabalho e a rua : Crianças e adolescentes no Brasil urbano dos anos 80 (pp. 133-150). 2. ed. São Paulo : Cortez.

Weber, M. (2004). A ética protestante e o "espírito" do capitalismo. São Paulo : Companhia das Letras. (Original publicado em 1904).

\section{RESUMOS}

Neste artigo, apresentamos algumas reflexões acerca do trabalho infanto-juvenil, abordando três tópicos : ideologias que sustentam o trabalho precoce ; subjetividade da criança e do adolescente em situação de trabalho e saúde do trabalhador infantil. A perspectiva teórica que sustenta nosso olhar é a Abordagem Bioecológica do Desenvolvimento Humano. A compreensão de trabalho 
infantil está embasada na definição da Organização Internacional do Trabalho, sendo aquele que priva as crianças de sua infância, potencial e dignidade. Na perspectiva ideológica, apontam-se algumas questões que sustentam a prática do trabalho infantil, para além dos fatores econômicos. o olhar acerca da subjetividade procura compreender o impacto dessa situação no desenvolvimento das crianças e adolescentes. $O$ tópico da saúde do trabalhador infantil, por sua vez, sistematiza os riscos e conseqüências do trabalho precoce. Finaliza-se apontando a produção científica incipiente da Psicologia brasileira acerca da temática.

En este artículo, presentamos algunas reflexiones sobre el trabajo infanto-juvenil, abordando tres temas: ideologías que sustentan el trabajo precoz; subjetividad de los niños y adolescentes en situación de trabajo y salud del trabajador infantil. La perspectiva teórica que sustenta nuestra mirada es la Abordaje Bioecológica del Desarrollo Humano. La comprensión del trabajo infantil está fundamentada en la definición de la Organización Internacional del Trabajo, aquel que priva los niños de su infancia, potencial y dignidad. En la perspectiva ideológica, señalase algunas cuestiones que embasan la práctica del trabajo infantil, para más allá de los factores económicos. La mirada acerca de la subjetividad comprende el impacto de esta situación en el desarrollo de niños y adolescentes. El tema de la salud del trabajador infantil, por su vez, sistematiza los riesgos y consecuencias del trabajo precoz. Se apunta también que la producción científica sobre esta temática en la Psicología brasileña aun es escasa.

Dans cet article, nous présentons quelques réflexions concernant le travail infantile et juvénile, en l'abordant selon trois axes : celui des idéologies qui soutiennent le travail précoce; celui de la subjectivité de l'enfant et de l'adolescent en situation de travail; et celui de la santé du jeune travailleur. La théorie qui soutient notre regard est celle de l'approche bioécologique du développement humain. La compréhension du travail infantile est basée sur la définition de 1 'Organisation Internationale du Travail, comme étant celui qui prive les enfants de leur enfance, de leur potentiel et de leur dignité. Dans la perspective idéologique, on reprend quelques questions qui, au-delà des facteurs économiques, soutiennent la pratique du travail infantile. La partie de cet article consacrée à la subjectivité cherche à comprendre l'impact de cette situation sur le développement des enfants et des adolescents. En ce qui concerne la santé du jeune travailleur, on systématise les risques et les conséquences du travail précoce. Cette contribution termine en situant la production scientifique concernant cette thématique, qui émerge dans le champ de la Psychologie brésilienne.

In this paper, we present some reflections concerning child labour, focusing on three topics : ideologies; subjectivity of the child and the adolescent who are involved in child labour; and child workers' health. The theoretical framework that we use is the Bio-ecological Theory of Human Development. The concept of child labour is based on the definition of the International Labour Organization (ILO) : activity that does not allow a child to live his/her childhood, to express his/her potential and to have dignity. Concerning the ideological perspective, some questions that support child labour are analyzed, beyond economic factors. The subjectivity approach attempts to understand the impact of child labour on the development of children and adolescents. The topic of child workers' health systematizes the risks and consequences of child labour. Initial scientific production on this matter in Brazilian Psychology is underlined. 
ÍNDICE

Mots-clés: travail infantile et juvénile, travail précoce, développement de risque, santé du jeune travailleur

Palavras-chave: trabalho infanto-juvenil, trabalho precoce, desenvolvimento de risco, saúde do trabalhador infantil

Keywords: child labour, premature work, development at risk, child workers' health

Palabras claves: trabajo infanto-juvenil, trabajo precoz, desarrollo de riesgo, salud del

trabajador infantil

\section{AUTORES}

\section{MAYTE AMAZARRAY}

Universidade Federal do Rio Grande do Sul, Rua Prof. Carvalho de Freitas, nº 611/1102 - Torre 2 CEP 91720 - 090 Porto Alegre/RS Brasil

maytepsi@gmail.com

\section{LUCIANA THOMÉ}

Universidade Federal do Rio Grande do Sul, Rua Prof. Carvalho de Freitas, № 611/1102 - Torre 2 CEP 91720 - 090 Porto Alegre/RS Brasil

lucianadt@terra.com.br

\section{MICHELE POLETTO}

Universidade Federal do Rio Grande do Sul, Rua Prof. Carvalho de Freitas, no 611/1102 - Torre 2 CEP 91720 - 090 Porto Alegre/RS Brasil

michelepolettopsi@gmail.com

\section{SÍLVIA KOLLER}

Universidade Federal do Rio Grande do Sul, Rua Prof. Carvalho de Freitas, nº 611/1102 - Torre 2 CEP 91720 - 090 Porto Alegre/RS Brasil silvia.koller@pq.cnpq.br 